University of Louisville

ThinkIR: The University of Louisville's Institutional Repository

Electronic Theses and Dissertations

$1-1924$

\title{
The effect of endocrines upon animal behavior.
}

J. Hubert Geyer

University of Louisville

Follow this and additional works at: https://ir.library.louisville.edu/etd

\section{Recommended Citation}

Geyer, J. Hubert, "The effect of endocrines upon animal behavior." (1924). Electronic Theses and Dissertations. Paper 492.

https://doi.org/10.18297/etd/492

This Master's Thesis is brought to you for free and open access by ThinkIR: The University of Louisville's Institutional Repository. It has been accepted for inclusion in Electronic Theses and Dissertations by an authorized administrator of ThinkIR: The University of Louisville's Institutional Repository. This title appears here courtesy of the author, who has retained all other copyrights. For more information, please contact thinkir@louisville.edu. 


\title{
UNIVERSITY OF LOUISVILLE
}

"THE EFFECT OF ENDOCRINES UPON ANIMAL BEHAVIOR"

\author{
A Dissertation \\ Submitted to the Faculty \\ Of the Graduate School of the \\ College of Arts and Sciences, in \\ Partial Fulfillment of the Requirements \\ For the Degree of \\ - master of science -
}

DEPARTMENT OF BIOLOGY

BY

J. HUBERT GEYER

1924 


$$
\underline{\mathrm{C}} \underline{\mathrm{O}} \underline{\mathbb{N}} \underline{\underline{T}} \underline{\underline{\mathrm{E}}} \underline{\mathbb{N}} \underline{\underline{T}} \underline{\mathrm{S}}
$$

Introduction

History of Animal Behavior

The Specific Problem

Materials and Methods

Discussion and Results

Summary and Conclusion

Bibliography
Page 1

Page 8

Page 21

Page 22

Page 30

Page 58

Page 62 
INTRODUCTION 
It is not the primary purpose of this present work to treat the problem of the evolution of behavior, but rather to give an analysis of animal behavior as observed. These observations may appear as simple tests, but they make possible a new way to measure the capacity and determine the rate of learning by the animal mind.

rrogress in learning takes place through increased variety and precision of the movements brought about by stimulation and is very clearly observed in Amoeba, where we find the production of varied movements and the resolution of one physiological state into another.

Thus the organism reacts no longer by trial, by the overproduction of movements, - but by a single fixed response, appropriate to the occasion. We often speak of these responses as reflexes, tropisms, habits, and instincts. These fixed responses can be firmly established and they will not give way until a long period intervenes and the old responses are modified or destroyed by a new environment. 
Observation and experiment show that many variations exist in the behavior of animals. It is known that organisms have developed special types of behavior, such as burrowing or muning along the bottom of a pond.

When a response has been established by many repetitions, the organism will lose all tendency to react in any other way than to the particular one in question. In the early period, during which the organism is establishing such a response, it will retain the power of attempting other methods of reaction, such as performing other movements. But these movements will be ineffectual, because the structures of the organism may not be best adapted to their performance. They will not relieve the organism from stimulation, hence they will be quickly exchanged for those movements which are effective. Then the organism will react always by those movements on which its structure is based. If these ineffectual movements are not observed, it will appear that the organism has been rigidly limited from the beginning to this one type of behavior.

There is the view that animal behavior is based largely on this selection from among varied movements and that there is a kind of retention of the selected movements . 
We often say that an animal perceives and we base this statement on our own observation that it reacts in some certain way. We might say that Amoeba perceives all classes of stimuli which we as individuals perceive. Then we base perceptions upon our own judgments.

The term "discrimination" means an observed" fact that animals, both invertebrate and vertebrate, react differently to different stimuli. It is known that raramecium has the power of discriminating between acids and alkalies. The Amoeba can discriminate an Euglena cyst from a grain of sand. This being true of unicellular forms, we may then say that all animals show the power to discriminate in some way or other.

The term "choice" is used when an organism accepts or reacts positively to some things. Organisms choose things which are an aid to their normal life process and reject those that do not. Choice is not perfect altogether, for inert substances are 'swallowed' by paramecium.

Behavior is based upon the method of trial and error, and this process makes use of action that is very similar to choice. Many scientists believe that 
the behavior of the infusorian is a process of choice and that choice is the necessary constituent of behavior.

In attention we find that the organism reacts to only one stimulus even if others are present. The organism then concentrates its efforts to one stimulus to which it responds.

It is known that stentor and Paramecium, while reacting to contact with a solid, are not influenced to any extent by heat, chemicals or electric current. Thus an organism reacts to one stimulus or the other, but not to both at the same time.

In the higher vertebrates, there are distinct conditions, as the "emotions", "feeling", "appetites", and "desires". The behavior depends upon the physiological condition of the organism, but in the lower organisms there are a number of states that are parallel. When the Hydre is observed, we notice that it opens its mouth widely when immersed in a nutritive liquid. The flatworm has a certain physiological condition when it moves about in hunting for food. This searching for food on the part of the individual is called a "desire" in higher animals.

If we continue our research all the way up the scale to man, we find that organisms react negatively to 
injurious and powerful agents. We speak of them as "pain" in man. When we view a wild beast, the sight is not injurious, but the after-thought causes a negative reaction and is called "fear". By careful study we notice that an organism moves and reacts in ways that are advantageous to it. If it gets into warm water, it tries to get out and the same is tmue of excessively cold water. If by accident it finds itself in an injurious chemical solution, it tries its best to swim into another medium. If there is not enough oxygen present in a certain place, then it goes to a region where it can secure it for respiration.

The term "behavior" then is used as a mere collective name for the most obvious and most studied of the responses of the organism. It is generally accepted that these responses are closely connected with and are outgrowths of the more recondite internal processes. They follow laws the same as those of other life processes. In our observations we can see not only what the animal does, but how this happens to be regulatory.

We know that anything injurious to the organism causes changes in its behavior and that these changes 
bring the organism into new conditions. As long as the injurious condition exists, the behavior changes continue.

If several changes of behavior take place successively that subject the organism to various possible conditions, a condition will finally be found that proves least injurious to the organism. Then the changes in behavior stop and the organism remains in the favorable condition.

Hawlow (1898) showed that the adaptive changes in the activities of the digestive glands, fitting the digestive juices to the food taken, do not occur instantIy and completely under a given diet, but are brought about gradually. As long as a dog is given a diet of bread, the pancreatic juice becomes more adapted to the digestion of starch. Thus various organs have certain possibilities of variation, which are due to the development of something corresponding to the "action system in behavior. In the pancreas there will be certain possibilities as regards chemical changes. This "action system" may be a production of quantities of enzymes.

Personal choice in man is usually conscious choice, but in other animals there is some doubt as to whether it is accompanied by consciousness. Thus we have the following processes:- 
1. Definite internal processes are occurring in organisms.

2. Interference with these processes causes a change of behavior and varied movements, subjecting the organism to many different conditions.

3. One of these conditions relieves the interference with the internal processes, so that the changes in behavior cease. 
HISTORY OF ANIMAL BEHAVIOR. 
-:- HLSTORY OF ANLMAL BEHAVIOR -:-

It has long been an established fact that in order to find new formulae and solve difficult problems, it is necessary to resort to experimentation. Yet it has only been within the last decade that scientific methods have been applied to the problem of the character and keenness of the "intellect" of the lower vertebrates.

There is abundant evidence that casual observations of the behavior of lower animals have been made and sometimes used to point a moral lesson, as in the well known statement of solomon in reference to the "industry" of the ant.

The inhabitants of Thrace for centuries have used the fox to test the strength of ice on a river before crossing it themselves. We know that the fox has a keen sense of hearing and listens to the roaring of the water beneath the surface of the ice and judges for himself whether the surface will support his weight.

Darwin, in his "Descent of Man", says - "as dogs, cats, horses and probably all higher animals, even birds, have vivid dreams, and this is shown by their movements and the sounds uttered, we must admit that 
they possess some power of imagination ${ }^{i \prime}$.

In 1890, Loeb advanced the theory that the responses of animals to stimulation, instead of being signs of "sensation", are analogous to the reactions of plants to such stimuli as light.

The idea that lower animals lack any characteristic resembling human consciousness in the sense of the present day meaning of that term seems very probable, but sensations, feelings and passions play an important part in the animal mind without involving thought.

It is almost impossible to fix a point where intelligence makes its first appearance. The intelligence of the higher Mollusca had, in all probability an independent origin from that of the Arthropoda, and the intelligence of the Vertebratea was probably developed independently of that of the other groups. Even among the Arthropods themselves it is not believed that the intelligence manifested by the Arachnids had a common origin with that of the Insects, and that in both of these large groups intelligence may have developed independently out of behavior of the purely instinctive type.

It is known that intelligence is not an entirely new power unrelated to the other activities of organic life, but that it is a process growing out of other 
organic functions; as Spencer has said "a higher phase of those processes of adjustment and regulation which make up the life of the animal ${ }^{i:}$

Wasmann defines intelligence as the power of reasoning by the general use of concepts. In Coelenterata, the behavior is of the reflex type and it is often highly plastic and capable of being modified in many ways as the result of previous experience. Echinoderms show a complex and plastic behavior to a certain degree, but little truth is known as to their power of forming associations. Preyer, in his investigations of the starfish, found indubitable indications of intelligent action, but Jennings and Glaser did not confirm Preyer's conclusions. It is known that the starfish can acquire habits of a certain kind, but it cannot form associations.

The power of associating certain appearances with food might be expected to occur among the earliest manifestations of intelligence. Miss Sondheim kept a damsel fly larva in a dish of water, where it was frequently fed. At the first feedings, the larva scuttled away in fear, but after several feedings, this "timidity" was overcome. Soon it would take flies from her fingers and would come toward her whenever she would approach. 
Wasmann trained a worker ant to eat honey from the end of a needle. Later the ant became so tame that it would accept honey from his finger. Insects, like higher animals, learn to avoid injurious substances which they at first attempted to use w food. Reuter placed some poisoned syrup near a nest of ants. Many of the ants partook of the syrup, but soon they ejected it and refused to eat any more. Forel believes that insects have ability to draw inferences from analogy. We have at some particular time noticed that animals meet obstacles or unusual situations and the solution of such confronting problems requires more than "mere instinct" Ants are said to be gifted with ingenuity, reason, and imagination.

Wasmann placed a few pupae in the center of a watch glass filled with water. The ants being nearby, soon brought some sand and threw it into the water in the watch glass until a passage was formed and the pupae were carried away.

Kirby and spencer, by careful observation, noticed a beetle which had made a pellet for the reception of its eggs. The beetle was unable to roll the pellet out of a depression into which it had fallen, even after many trials. She then went to a colony and returned with three companions who succeeded in 
moving the ball. out of the depression. This example shows that insects must have some means of communication and of receiving information.

A populous ant colony will make an attack upon a neighboring nest, while a small colony will seek safety. The ants stay close together in their long expeditions and follow their scouts.

The means of communication noticed are striking with the antennae, butting with the head, opening the jaws, beating the floor with the abdomen, and the production of sounds of various degrees of intensity.

Wasmann has compiled a sort of vocabulary of signs made by the antennae-- a "Worterbuch der Fuhlersprache", which is about as extensive as Garner's "Language of Apes".

By the vigor and frequency of the strokes of the antennae, the one ant may inform another about food, danger, and cooperate in various kinds of manual work. The fundamental law of all learning is the Law of repetition. The nervous process that takes place traverses a certain pathway in the nervous system. It has been found that sea-anemones are able to distinguish between real food and filter paper soaked in foodjuice. Several such experiences enable the individual to distinguish more readily the real from the artificial food. Fleur and Walton believe that true learning is involved here. 
Yerkes trained an earthworm, by giving it an electric shock when it followed its innate inclination to turn towards a darkened region, to turn away and towards the light. Szymanski succeeded in training the cockroach to go to the lighted part of a box even though it always preferred the darkened.

The instinct in the above cases is completely suppressed by punishment. Iunishment gives an unpleasant feeling or sensation that causes the animal to take the path where he will not experience it. It may be true that the animal does not compare the light with the dark passage, but learns to distinguish the passage to be avoided.

The punishment inflicted by the electric shock is a very important factor. Some animals are more sensitive than others. Yerkes is given the credit of being the first man to use the electric shock as a means of training animals. He tried to educate a frog to make a turning to the right. The frog would sometimes sit motionless, so he employed the electric shock to induce greater activity. He also expeximented upon the relation of the strength of the punishment to the difficulty of the discrimination required of the animal. It was found that weaker punishments were more effective in the learning of hard discriminations 
and stronger punishments in the case of easky discriminations. Dodson, on the contrary, found that the hardest discriminations were acquired by kittens in 825 trials with a moderate stimulus; but 107.5 trials were required in the case of a strong stimulus.

Wodsedalek showed that immature mayflies could be trained by feeding to overoome their innate response to light. This insect has a strong tendency to avoid light and hide under stones in water. He fed them daily on the upper surface of a stone and succeeded in overcoming this reaction. All that was required to bring the mayfly from its hiding place, was to jar the dish and the insect would come to the upper surface of the rock and hasten to the feeding place. The earthworm will not respond to light if it is feeding or mating. It has been found that sea-urchins interlace their spines when a solution of weak acid is dropped into their midst. A slight shaking will restore them to their normal position, but if more acid is added, no mechanical stimulation will overcome the effect of the chemical.

It is known that an animal should be able to respond to a very faint food stimulus rather than to any of the stronger forces acting upon it. Thus the prime need of animal life is some arrangement whereby 
weak, but important stimuli shall be given the preference in determining reaction over stronger, but less vitally necessary ones. A little chemical energy given out by a bit of food may effect the nerrous system to a great extent. Light stimuli may involve an insignificant amount of energy in comparisoh to other forces.

It follows then that instinct unmodified by experience is adapted to general rather than to special features of environment. Then individual experience brings to light the importance of certain particular stimuli. A rabbit crouching motionless, watching each movernent of a possible enemy, gives an example of breathless attention.

Small demonstrated that rats may be trained to dig for food. He buried food in saw-dust at the posterior end of a long box and found that it required one and one-half hours for the animal to dig in the right place the first day. It took eight minutes on the second day and thirty seconds on the thirteenth day. Cole ${ }^{i} \mathrm{~s}$ experiments with the recoon show that this animal is midway between the monkey and the cat in rate of learning. Both animals learned combination locks and showed a tendency to go through certain motions immediately.

Many animals use landmarks to guide themselves on 
their return home. Holmes observed that the wasp, on leaving its nest in search of food for its young, makes an extensive flight about its locality. On returning home with its prey, the insect retraces its flight by certain landmarks previously noted. This learning is rapid and temporary.

It is supposed that cats and dogs dream because they snarl and twitch in their sleep. Some animals show a marked depression during their master's or mistress ${ }^{\prime}$ absence.

There are certain factors that affect an animal's behavior:-

1. Its age. Yerkes showed that the young dancing mouse learns to discriminate faster than an older animal.

2. That sex is an important factor was shown by Yerkes in the case of dancing mice. The males of this species learn faster than the females.

3. The number of trials per day has a remarkable affect upon the speed of the learning. Ulrich has shown that whife rats learn the puzzle-box habit in a shorter time with fewer trials per day, say one, than with three or five per day. In some instances marked improvement is secured when the animal has only one trial every third day. We know by exper- 
ience that the best way to memorize

a passage is not to try to learn it at once, but to repeat it now and then. This is known as the "set method".

4. By learning one habit other habits may be more easily acquired. Yerkes showed that dancing mice which have learned one maze, learn another one more rapidly than those that have had no previous training.

5. Animals differ greatly according to ability. Wodsedalek showed that a certain mayfly was especially talented. Many experimenters have reported similar individual variations.

Forel found that humble-bees have the capacity to distinguish between a blue circle and a strip of blue paper. An English sparrow and a cowbird learned to discriminate between a card bearing three horizontal bars and one bearing a black diamond.

Sir John Lubbock taught his poodle "Van" to pick out cards marked "Food", "Bone", "Out" and "Water", and to present each one when mentioned or indicated by its master. It required ten days to make the first step in discriminating between a printed and a plain card; a month was required to perfect it; and it took twelve days before Van would pick the right card whenever he wanted food or water. Out of the 113 trials noted, only two mistakes were made. 
In the rat we find a high development of qualitative discrimination in the sense of smell. Persons who have had the experience in hunting, know that wild animals can protect themselves by this keen sense. We have noticed that the domesticated dog or cat in a distant room is awakened from its slumber by the presence of odors from food being prepared in the kitchen. The keen smelling sense is highly developed in such dogs as blood hounds.

In as high a vertebrate as the rat, we see evidence of past experience. The animal is affected in his present actions by the result of previous stimuli. Its method of choice is trial and error. A chemical or physical stimulus acting repeatedly upon an individual animal produces unpleasantness that finally becomes "unbearable". Then the animal sets to work to find a way to get rid of the irritating stimulus. But after long exposure to this stimulus, it is no longer felt; the animal ceases its movement and has attained to what is known as a state of adaptation. In this state of adaptation, the sense organ becomes incapable of responding to the stimulus. Persons who work in bakeries, drug stores and other places where certain odors are present, find that they are unable to detect the odors after a certain period of time. 
Small has found that white rats show evidence of a very simple kind of imitation. He says that when one rat sees another digging, it will dig also; if one runs over a box, others will follow. Berry claims to have found evidence of intelligent imitation. "When two rats were put into a box together, one rat being trained to get out of the box and the other untrained, at first, they were indifferent to each other's presence, but as the untrained rat observed that the other one was able to get out while he was not, a gradual change took place. The untrained rat began to watch the other closely; he followed him all about the cage, standing up on his hind legs beside him at the string, and pulling it after he had pulled it. We also saw that when he was put back, the immediate vicinity of the loop was the point of greatest interest for him, and that he tried to get out by working at the spot where he had seen the trained rat try."

It was noted that the untrained rat showed little interest in the actions of the trained one until he found that his trained brother knew how to make his escape from the cage. In a case like this, we cannot regard this imitation as a series of congenital responses to the perception of particular movements. The rat goes 
through the similar motions in order to release himself from the cage and by keen observation, he notices the movements necessary for his own deliverance. 
THE SPECIFIC PROBLEM. 


\section{-:- THE SFECIFIC PROBLEM - :-}

The problem of this present work is to determine the "Effect of Endocrines upon Animal Behavior". It is a consideration of the internal secretions or "incretions" of the various organs and their reaction upon the rate of learning of a mammal; the factor of age and its relation to the rate of learning in the problem box method; a comparison of the time required In learning a problem to that of forgetting the same problem, with special reference to the individual animals. The advance of experimental biology with its various methods for observing and comparison of the above stated problems has made possible a more comprehensive understanding of why animals act as they do. Thus animal behavior has blossomed into an experimental science with a rich background of both the biological and psychological sciences. The problem box method of making discriminations, which requires an analysis on the part of the individual animal in making a "correct" choice, is very satisfactory in the determination of rates of learning. In the present problem it is applied in the determination of possible modifications in that rate arising as the result, perhaps, of modified physiological processes concomitant upon the oral administration of incretion products. 
MATERIALS AND METHODS. 


\section{-:- MATERIAIS \& METHODS -:-}

Domesticated rats were selected for these experiments. It is obvious that a diverse heredity might cause consistent differences in the rate of learning; therefore, the experimental and control groups of animals were composed of litter brothers and sisters; litters of rats were divided into two equal groups and the two halves of each litter were assigned, one to the experimental group and one to the control group. The animals of experiments $A$ and $B$ were albinos; those of experiments $D$ and $F$ were yellows, Hellow-hooded, and gray-hooded. These pigmented individuals were obtained by breeding yellows and yellow-hooded rats to albino rats. The stock animals were obtained from the Bussey Institution of Harvard University, through the courtesy of Professor W. E. Castle, to whom I am grateful for the formula of the whole dry food used for rats in that Institution.

The animals were housed in cages, the floor of which is a square wooden frame, built of strips $11 \frac{1}{2}$ inches $x$ $11_{\overline{2}}$ inches and covered with a one-fourth inch galvanized wire mesh. The wall of the cage is a cylinder of this same galvanized wire mesh, 9 inches in diameter. This wire cylinder was made by raveling out the edges of the mesh and using the projecting wires to fasten the 
two ends together. The resulting cylinder was fastened at the base in the same manner. The top of the cage is formed precisely as the base, but is not fastened to the cylinder, in order to be used as a door. The escape of the animal is prevented by weighting the top. This type cage was devised by Dr. A. W. Homberger for use in studies of animal nutrition in the Department of Chemistry of the University of Louisville and I am glad to acknowledge his kind permission to use it for my purposes also.

A "compound" cage is also in use, which was devised in this laboratory with the assistance of Mr. S. H. Matlack of Louisville, Ky. This cage consists of four tiers of five compartments each. Each tier is separated from that next above it by a space $2 \frac{1}{2}$ inches high, where fresh sheets of paper were placed at regular intervals to provide for the removal of droppings. The compartments are $11 \frac{0}{4}$ inches wide, $9 \overline{4}$ inches high and 15 inches from front to back. These compartments are covered with $\frac{1}{4}$ inch galvanized wire mesh, with the exception of the top of the cage. The top of each tier, with the exception of the upper tier, is a single sheet of galvanized metal. Further, the partition between the first and second, and that between the fourth and fifth compartments of each tier are also of galvanized metal. Each compartment is provided with 
a galvanized door $6 \frac{3}{4}$ inches square hinged at the top and provided with fasteners. These-" "hinges" and "fasteners" were devised by Mr. S. H. Matlack.

Two other compound breeding cages are in use. These were also devised by Mr. Matlack and they are constructed in the same manner as the above, except that each compound cage consists of four vertically arranged compartments 49 inches high, 24 inches wide, and 15 inches from front to back.

The problem box used is a rectangular wooden box

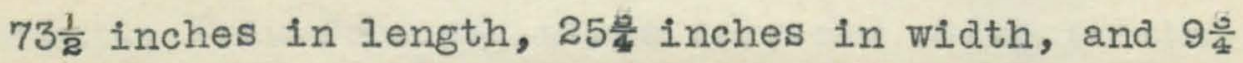
inches in depth, with an entrance $4 \frac{1}{4}$ inches $\times 4 \frac{1}{4}$ inches at one end. The entrance may be closed by a sliding door, which moves in a vertical direction in grooves on the outside of the problem box. A partition, dividing the greater part of the length of the box into narrow right and left compartments, extends along its mid-line from a point $15 \frac{1}{2}$ inches from the entrance to the opposite end of the box. Each of these narrow compartments, or mun-ways, has its end, opposite the entrance-end, partitioned off by a cross-partition 14 inches from that end, to form a light-tight compartment 14 inches $\times 127 / 8$ inches. In the center of each of these cross-partitions there is a ground glass window 4 inches square. Each of these small compartments contains a 40-watt electric light bulb controlled by a switch on the outside of the left side of the problem 
box, near its entrance end. The entire box is painted a dull black.

On the floor, in front of the entrance, there is a pair of ginc plates and in front of each ground glass window there is another similar pair of zinc plates. These electrodes are connected with two "medical induction colls" in such a way that a current may be passed at will through any pair of them. In front of each ground glass window is set a small cocotte, one containing a small quantity of food, the other one empty. This food was whole corn and owing to the length of the run-ways, the factor of smell was eliminated.

This box is, therefore, arranged for the use of "punishment and reward" in "teaching" the animal and also to guard against the formation of a "direction habit", since either window may be illuminated and the cocottes interchanged at will.

The experimental room is a room, located near the animal room on the second floor of the Biology Building. The floor space of this room is $16 \frac{3}{4}$ feet $\times 3$ feet. There is a door at the anterior end and this is the only opening into the experimental room, which is both light-proof and sound-proof. 


\section{THE PROBLEM BOX}
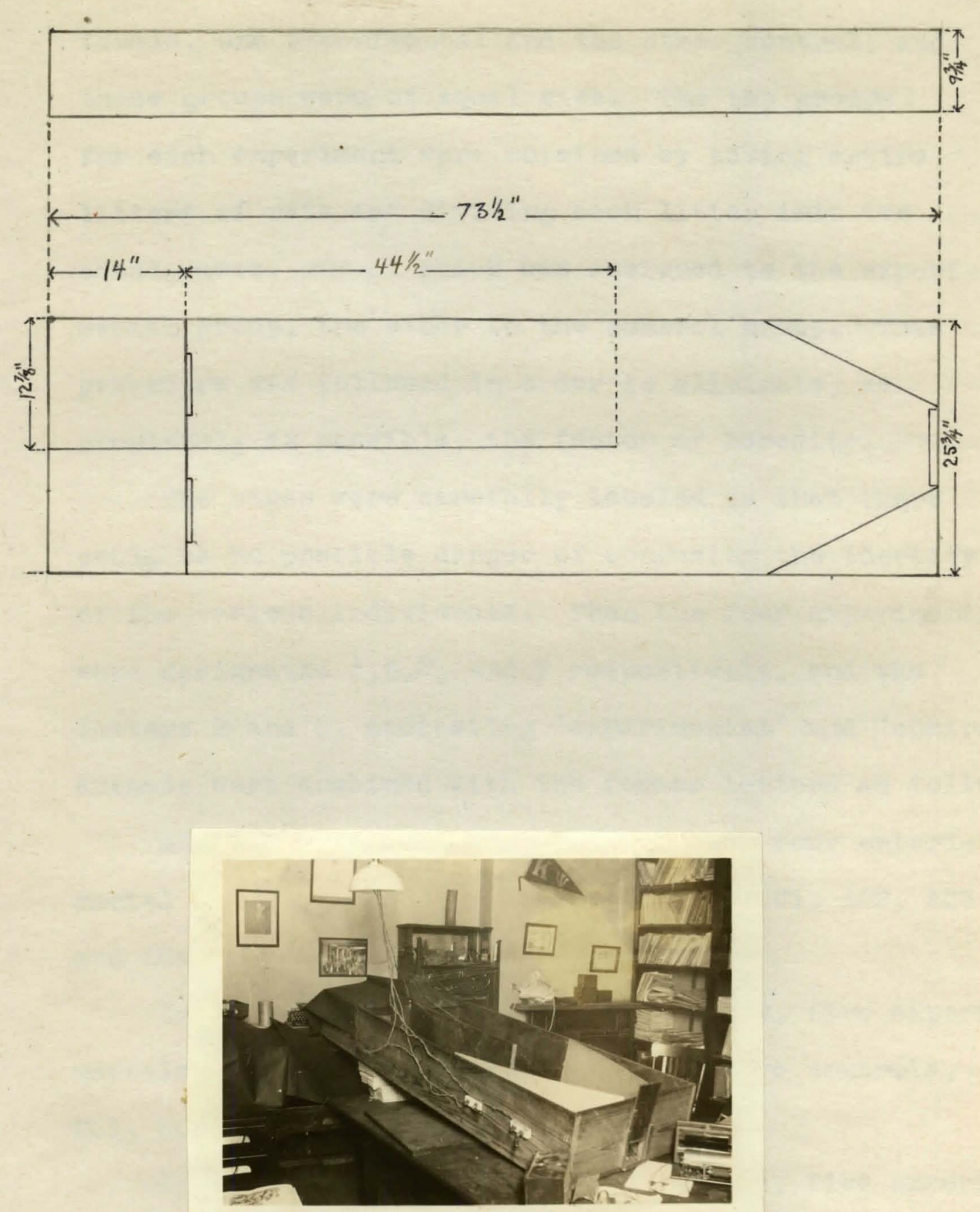
Each experiment concerned two groups of individuals, one experimental and the other control, and these groups were of equal size. The two groups for each experiment were obtained by taking entire litters of rats and dividing each litter into two equal parts, one of which was assigned to the experimental group, the other to the control group. This procedure was followed in order to eliminate, as completely as possible, the factor of heredity.

The cages were carefully labeled so that there could be no possible danger of confusing the identity of the various individuals. Then the four experiments were designated $A, B, D$, and $F$ respectively, and the letters $\mathrm{E}$ and $\mathrm{C}$, indicating "experimental" and "control" animals were combined with the former letters as follows:

$A E 1, A E 2, A E 3$ and $A E 4$ designate the four experimental individuals of Experiment $\mathrm{A}$; and $\mathrm{ACl}, \mathrm{AC2}, \mathrm{AC3}$ and AC4, their corresponding controls.

In Experiment B, there were ten rats, five experimentals, $\mathrm{BE} 1, \mathrm{BE} 2, \mathrm{BE} 3, \mathrm{BE} 4, \mathrm{BE} 5$; and five controls, $\mathrm{BCl}, \mathrm{BC} 2, \mathrm{BC} 3, \mathrm{BC} 4, \mathrm{BC} 5$.

In Experiment $D$, there were ten rats, five experimentals, $\mathrm{DE} 1, \mathrm{DE} 2, \mathrm{DE} 3, \mathrm{DE} 4, \mathrm{DE} 5$; and five controls, $\mathrm{DC} 1, \mathrm{DC} 2, \mathrm{DC} 3, \mathrm{DC} 4, \mathrm{DC} 5$.

In Experiment $F$ there were six rats, three experimentals, FEl, FE2, FE3; and three controls, FCl, FC2, FC3. 
Food and water were served in small individual custard cocottes, three inches in diameter. These are of pottery but porcelain lined. The food consisted of bread and milk, the latter being furnished gratis by the Gray Von Allmen Company, Louisville, Ky•, to whom I wish to express my sincere appreciation of this courtesy. The food was served daily after the animals had been run in the problem box. The experimental rats were fed the hormotone in dosages varying from * to 1 gram, mixed with the bread and milk. At various times such green material as kale was fed to keep the diet as balanced as possible.

The conthiners used for the dry food are small galvanized iron boxes 5 inches $x 5$ inches $\times 3$ inches. The top, similar to that of an ordinary cuspidor, could be removed from the box. The hole at the center of the top is $13 / 16$ inches in diameter, which is precisely large enough to permit the entrance of the head of the animal, but not the body. We are indebted to Frof. W. E. Castle of the Bussey Institution for a description of these dry food boxes. The dry food was prepared according to the following formula, furnished to us by rrofessor Castle: Rolled oats, 5 parts by volume; hominy, 3 parts by volume; powdered milk, $l_{\bar{Z}}$ parts by volume; beef scrap, $2 \overline{\bar{z}}$ parts by volume; and a trace of salt. In addition, dog biscuits were kept wired to the 
sides of the cages.

The material used for bedding is known to the trade as Waxed Paraffin Clippings.

The rats were placed in the problem box individually. The room was kept totally dark. The food was placed before the unlighted window for the $A$ and $B$ series and before the lighted window for the $D$ and $F$ series. When the animals of Experiments $A$ and $B$ went to the lighted window of the problem box that was, of course, an incorrect choice and the animal in question was given an electric shock. When animals of Experiments $D$ and $F$ went to the unlighted window, they likewise were given an electric shock. Correct choices were rewarded by finding food. The light was shifted at irregular intervals as well, in order to prevent the formation of a "direction habit".

In case the animal did not move after it entered the problem box, it was given a slight shock, but not sufficient to cause him to make a hasty choice.

Each rat was given ten trials each day. The choice, correct or incorrect as it might be, the direction, and the date were recorded in a book kept for that purpose. 
DISCUSSION AND RESULTS

$\stackrel{2}{2}$ 
The albino rats used in Experiment $A$ were born on April 5, 1923. On June 1st, experimental feeding was begun. They were given one-half gram of hormotone daily for the succeeding period of 164 days. Then each individual, experimental and control, was subjected to the problem box training until he had mastered his problem. This was considered accomplished when the animal had made one hundred consecutive correct choices, at the rate of ten per day. The feeding of hornotone was continued with each individual until he had solved his problem as stated above. 
EXPERIMENTAI SERIES I.

$A E 1 ; A E 2 ; A E 3 ; A E 4$.

Days .

Number of mistakes.

Average number of Mistakes for each rat.

$\begin{array}{lll}1 & 20 & 5 \\ 2 & 22 & 5.5 \\ 3 & 20 & 5 \\ 4 & 18 & 4.5 \\ 5 & 12 & 3 \\ 6 & 9 & 2.25 \\ 7 & 6 & 1.5 \\ 8 & 13 & 3.25 \\ 9 & 3 & 0.75 \\ 10 & 3 & 0.75 \\ 11 & 3 & 0.75 \\ 12 & 2 & 0.5 \\ 13 & 1 & 0.25 \\ 14 & 1 & 0.25 \\ 15 & 2 & 0.5 \\ 10 & 1 & 0.25 \\ 17 & 0 & -2\end{array}$


CONTROL SERIES I.

$A C 1 ; A C 2 ; A C 3 ; A C 4$.

Days. Number of mistakes.

Average number of Mistakes for each rat.

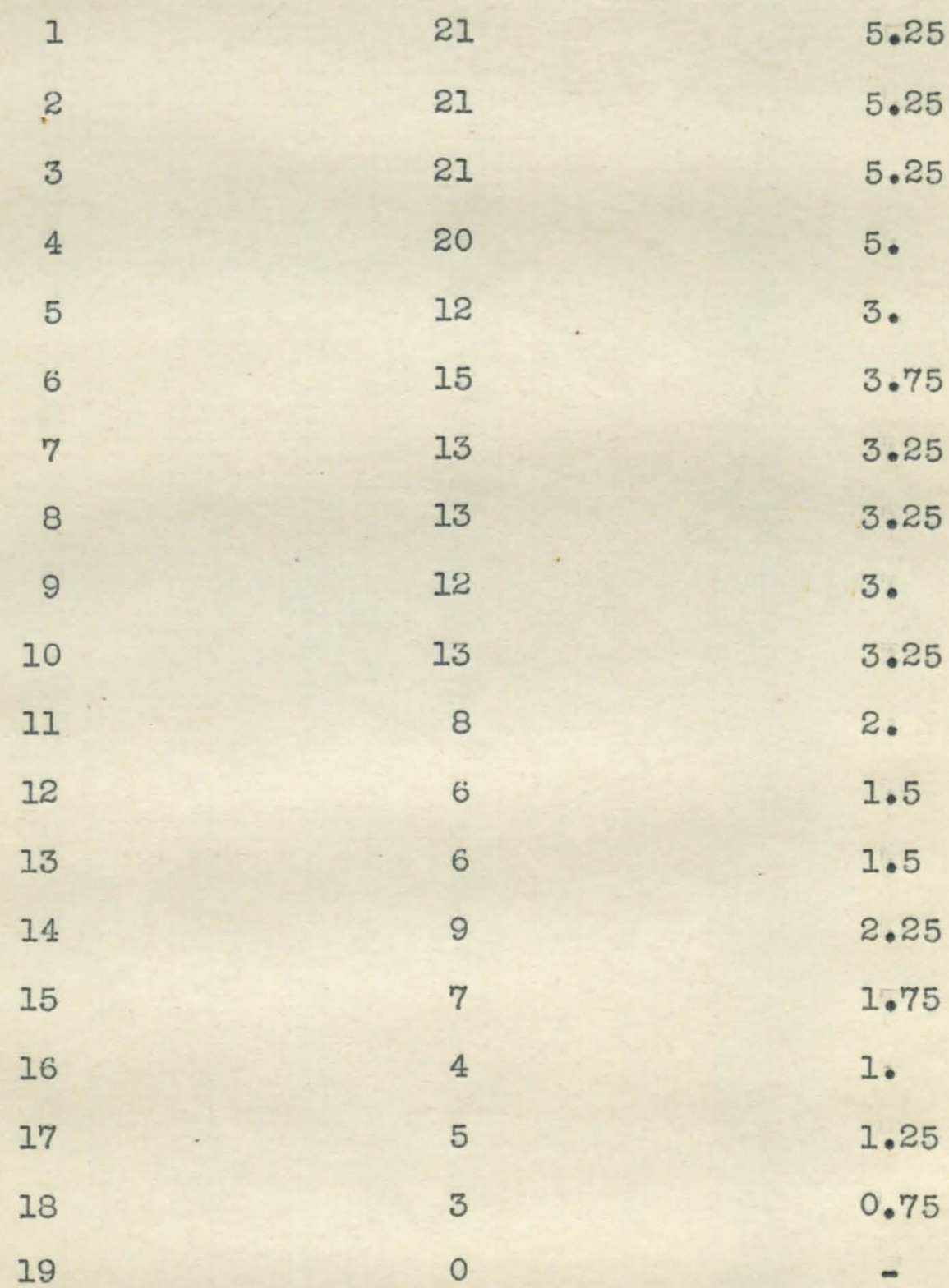


EXPFRLNENTAIS AND CONTROIS--SERIES I

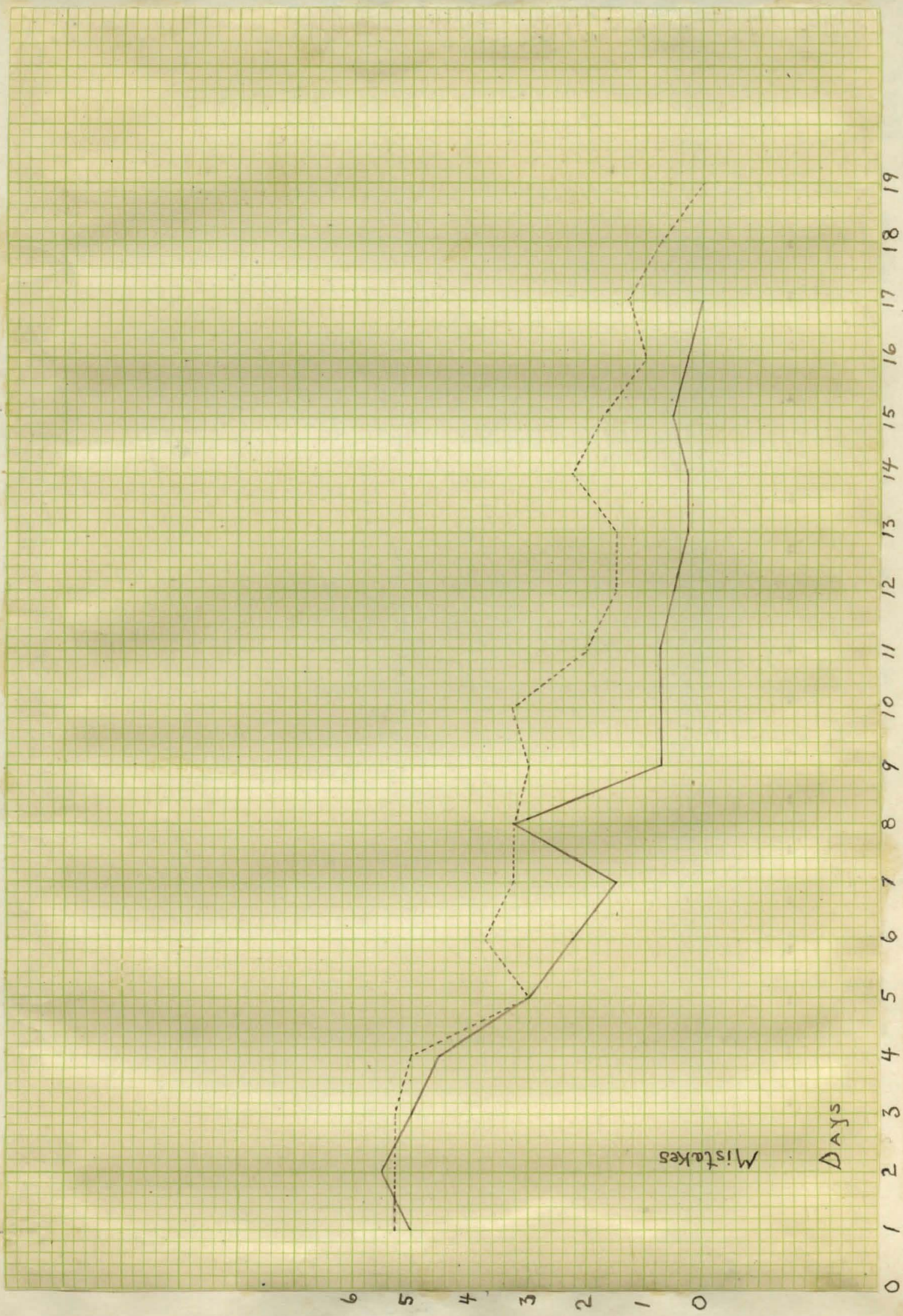




$$
\underline{S} \underline{E} \underline{R} \underline{I} \underline{E} \underline{S} \quad \underline{I}
$$

Days. Average no. of Average no, of Average excess per mistakes per rat. mistakes per rat. rat of control (Experimental) (Control)

\begin{tabular}{|c|c|c|c|}
\hline 1 & 5. & 5.25 & 0.25 \\
\hline 2 & 5.5 & 5.25 & -0.25 \\
\hline 3 & 5. & 5.25 & 0.25 \\
\hline 4 & 4.5 & 5. & 0.5 \\
\hline 5 & 3. & 3. & - \\
\hline 6 & 2.25 & 3.75 & 1.5 \\
\hline 7 & 1.5 & 3.25 & 1.75 \\
\hline 8 & 1.25 & 3.25 & 2. \\
\hline 9 & 0.75 & 3. & 2.25 \\
\hline 10 & 0.75 & 3.25 & 2.5 \\
\hline 11 & 0.75 & 2. & 1.25 \\
\hline 12 & 0.5 & 1.5 & 1. \\
\hline 13 & 0.25 & 1.5 & 1.25 \\
\hline 14 & 0.25 & 2.25 & 2. \\
\hline 15 & 0.5 & 1.75 & 1.25 \\
\hline 10 & 0.25 & 1. & 0.75 \\
\hline 17 & - & 1.25 & 1.25 \\
\hline 18 & - & 775 & .75 \\
\hline 19 & - & - & - \\
\hline
\end{tabular}
over experimental. 
EXXESS OF CONTROLS OVER EXPERIMENTALS - SERIES I.

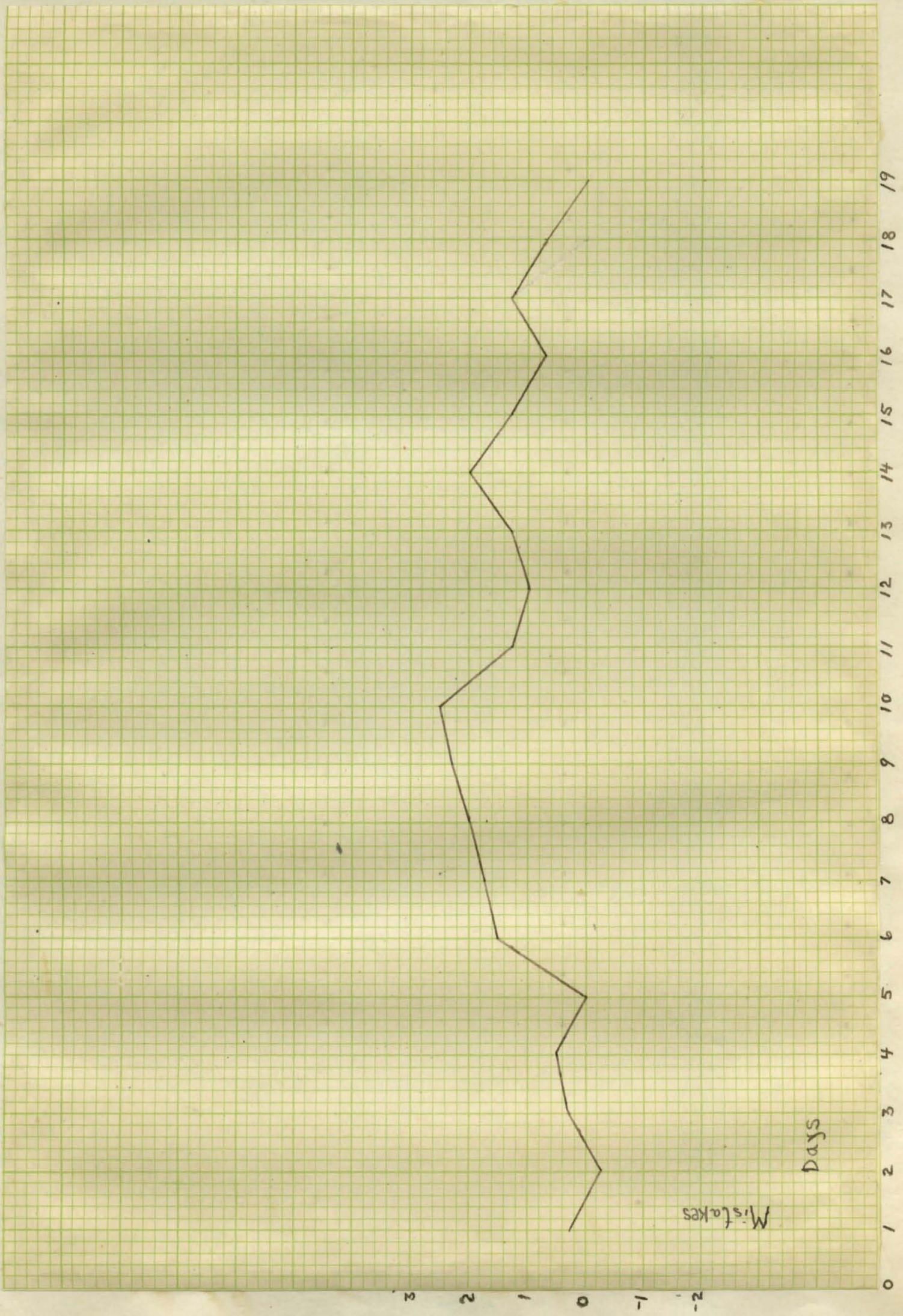


The albino rats used in Experiment $B$ were born on July 15, and 17, 1923. On August loth, experimental feeding was begun. They were given $4 / 5$ gram of hormotone daily for the succeeding period of 63 days. Then each individual, experimental and control, was subjected to the problem box training until he had mastered his problem. This was considered accomplished when the animal had made one hundred consecutive correct choices, at the rate of ten per day. The feeding of hormotone was continued with each individual until he had solved his problem as stated above. 


$$
-37-
$$

EXYERIMENTAL SERIES 2.

$\mathrm{BE} 1 ; \mathrm{BE2} ; \mathrm{BE} 3 ; \mathrm{BE} 4 ; \mathrm{BE} 5$.

Days. Number of Mistakes. Average number of Mistakes for each rat.

\begin{tabular}{|c|c|c|}
\hline 1 & 31 & 6.2 \\
\hline 2 & 28 & 5.6 \\
\hline 3 & 23 & 4.6 \\
\hline 4 & 22 & 4.4 \\
\hline 5 & 13 & 2.6 \\
\hline 6 & 8 & 1.0 \\
\hline 7 & 9 & 1.8 \\
\hline 8 & 5 & 1. \\
\hline 9 & 5 & 1. \\
\hline 10 & 2 & 0.4 \\
\hline 11 & 5 & 1. \\
\hline 12 & 2 & 0.4 \\
\hline 13 & 2 & 0.4 \\
\hline 14 & 4 & 0.8 \\
\hline 15 & 2 & 0.4 \\
\hline 16 & 3 & 0.6 \\
\hline 17 & 2 & 0.4 \\
\hline 18 & 1 & 0.2 \\
\hline 19 & 3 & 0.6 \\
\hline 20 & 0 & - \\
\hline
\end{tabular}


CONTROL SERIES 2.

$\mathrm{BC} 1 ; \mathrm{BC2} ; \mathrm{BC} 3 ; \mathrm{BC} 4 ; \mathrm{BC} 5$.

Days. Number of Mistakes. Average number of

\begin{tabular}{|c|c|c|}
\hline 1 & 28 & 5.6 \\
\hline 2 & 25 & 5. \\
\hline 3 & 21 & 4.2 \\
\hline 4 & 14 & 2.8 \\
\hline 5 & 17 & 3.4 \\
\hline 6 & 17 & 3.4 \\
\hline 7 & 14 & 2.8 \\
\hline 8 & 15 & 3. \\
\hline 9 & 12 & 2.4 \\
\hline 10 & 13 & 2.6 \\
\hline 11 & 13 & 2.6 \\
\hline 12 & 11 & 2.2 \\
\hline 13 & 11 & 2.2 \\
\hline 14 & 12 & 2.4 \\
\hline 15 & 8 & 1.6 \\
\hline 16 & 8 & 1.6 \\
\hline 17 & 7 & 1.4 \\
\hline 18 & 6 & 1.2 \\
\hline 19 & 3 & 0.6 \\
\hline 20 & 1 & 0.2 \\
\hline 21 & 0. & - \\
\hline
\end{tabular}


EXPERIMENTAIS AND CONTROLS -- SERIES 2.

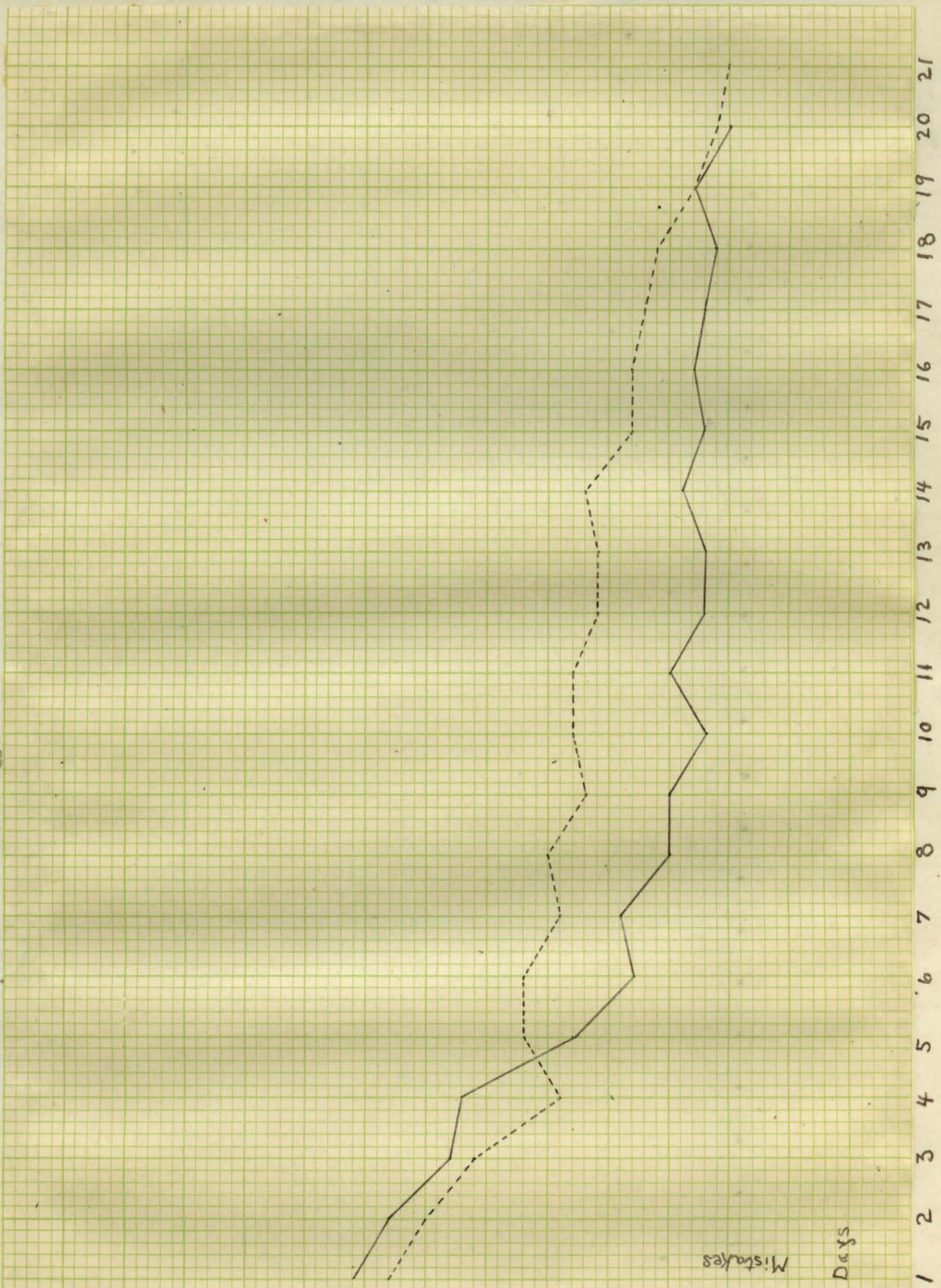

in $6 \ln \rightarrow m a-0$ 


$$
\underline{S} \underline{E} \underline{I} \underline{E} \underline{\mathrm{S}} \quad \underline{2} .
$$

Days. Herage no. of Average no of Average excess per mistakes per rat. mistakes per rat. rat of control over (Experimental) (Control)

\begin{tabular}{|c|c|c|c|}
\hline 1 & 6.2 & 5.6 & -0.8 \\
\hline 2 & 5.6 & 5. & -0.6 \\
\hline 3 & 4.6 & 4.2 & -0.4 \\
\hline 4 & 4.4 & 2.8 & -1.6 \\
\hline 5 & 2.6 & 3.4 & 0.8 \\
\hline 6 & 1.6 & 3.4 & 1.8 \\
\hline 7 & 1.8 & 2.8 & 1. \\
\hline 8 & 1. & 3. & 2. \\
\hline 9 & 1. & 2.4 & 1.4 \\
\hline 10 & 0.4 & 2.6 & \\
\hline 11 & I. & 2.6 & 1.6 \\
\hline 12 & 0.4 & 2.2 & 1.8 \\
\hline 13 & 0.4 & 2.2 & 1.8 \\
\hline 14 & 0.8 & 2.4 & 1.6 \\
\hline 15 & 0.4 & 1.6 & \\
\hline 16 & 0.6 & 1.6 & I. \\
\hline 17 & 0.4 & 1.4 & 1. \\
\hline 18 & 0.2 & 1.2 & 1. \\
\hline 19 & 0.6 & 0.6 & \\
\hline 20 & - & 0.2 & 0. \\
\hline 21 & - & - & \\
\hline
\end{tabular}
experimental. 
EXGESS OF CONTROLS OVER EXFERIMENPAIS - SERIES 2.

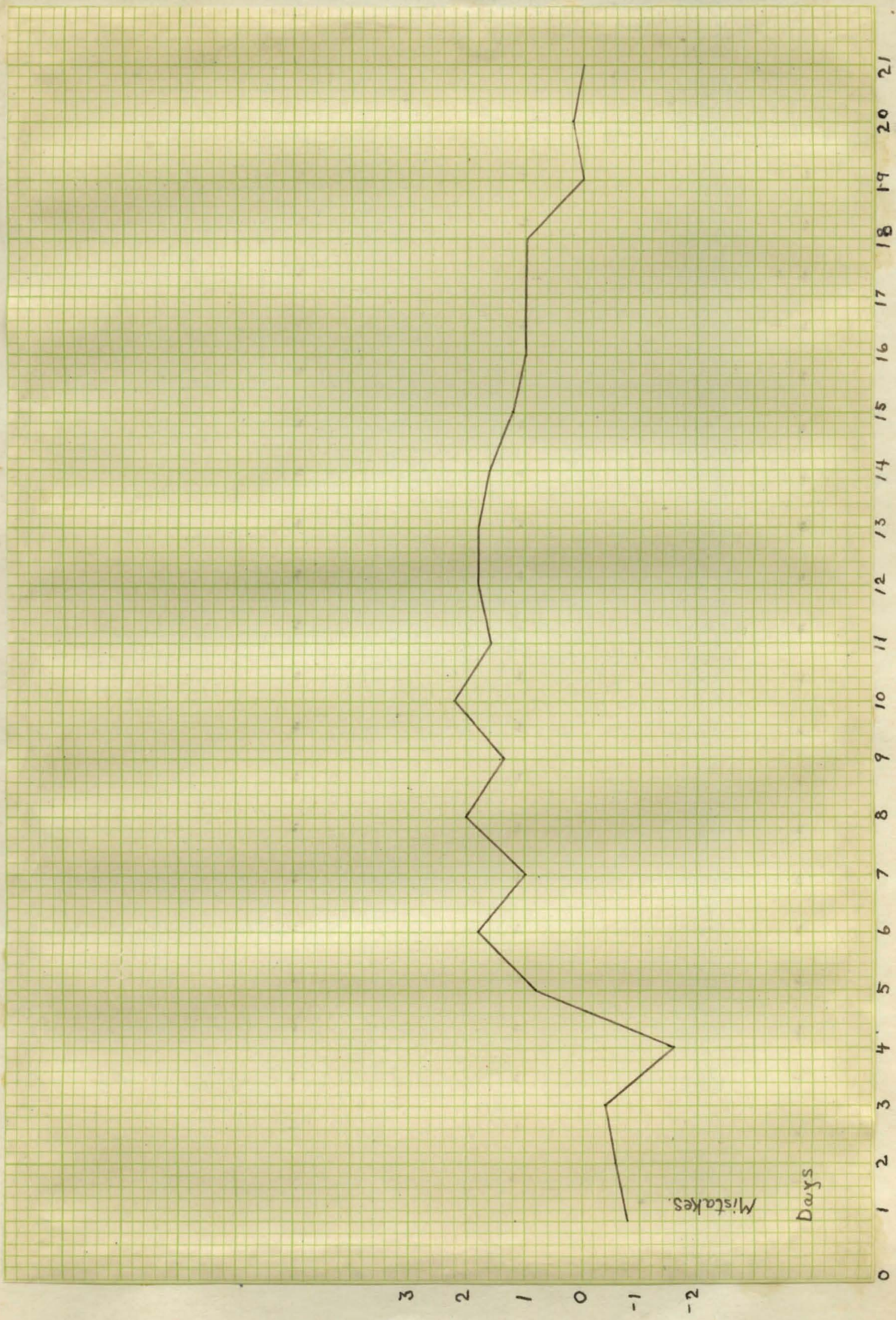


The yellow hooded rats of Experiment $D$ were born on May 2, and 8, 1923. On June 1st, experimental feeding was begun. They were given $2 / 3$ gram of hormotone daily for the succeeding period of 147 days. Then each individual, experimental and control, was subjected to the problem box training until he had mastered his problem. This was considered accomplished when the animal had made one hundred consecutive choices, at the rate of ten per day. The feeding of hormotone was continued with each individual until he had solved his problem as stated above.

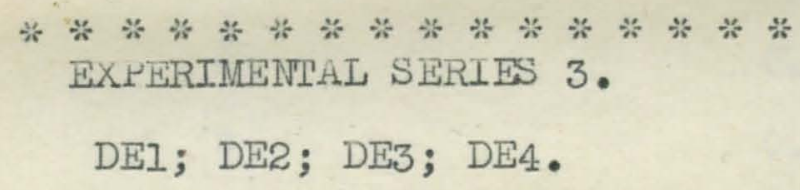

Days. Number of Mistakes. Average number of mistakes for each rat.

$\begin{array}{lll}1 & 21 & 5.25 \\ 2 & 29 & 7.25 \\ 3 & 22 & 5.5 \\ 4 & 11 & 2.75 \\ 5 & 17 & 4.25 \\ 6 & 8 & 2 . \\ 7 & 1 & 0.25 \\ 8 & 1 & 0.25 \\ 9 & 0 & -\end{array}$


CONTROL SERIES 3.

$\mathrm{DC} 1 ; \mathrm{DC2} ; \mathrm{DC} 3 ; \mathrm{DC} 4 ; \mathrm{DC} 5$.

Days. Number of Mistakes. Average number of mistakes for each rat.

$\begin{array}{lll}1 & 26 & 5.2 \\ 2 & 23 & 4.6 \\ 3 & 26 & 5.2 \\ 4 & 19 & 3.8 \\ 5 & 15 & 3 \cdot \\ 6 & 13 & 2.6 \\ 7 & 10 & 2.6 \\ 8 & 8 & 1.6 \\ 9 & 3 & 0.0 \\ 10 & 2 & 0.4 \\ 11 & 3 & 0.6 \\ 12 & 2 & 0.4 \\ 13 & 0 & -\end{array}$




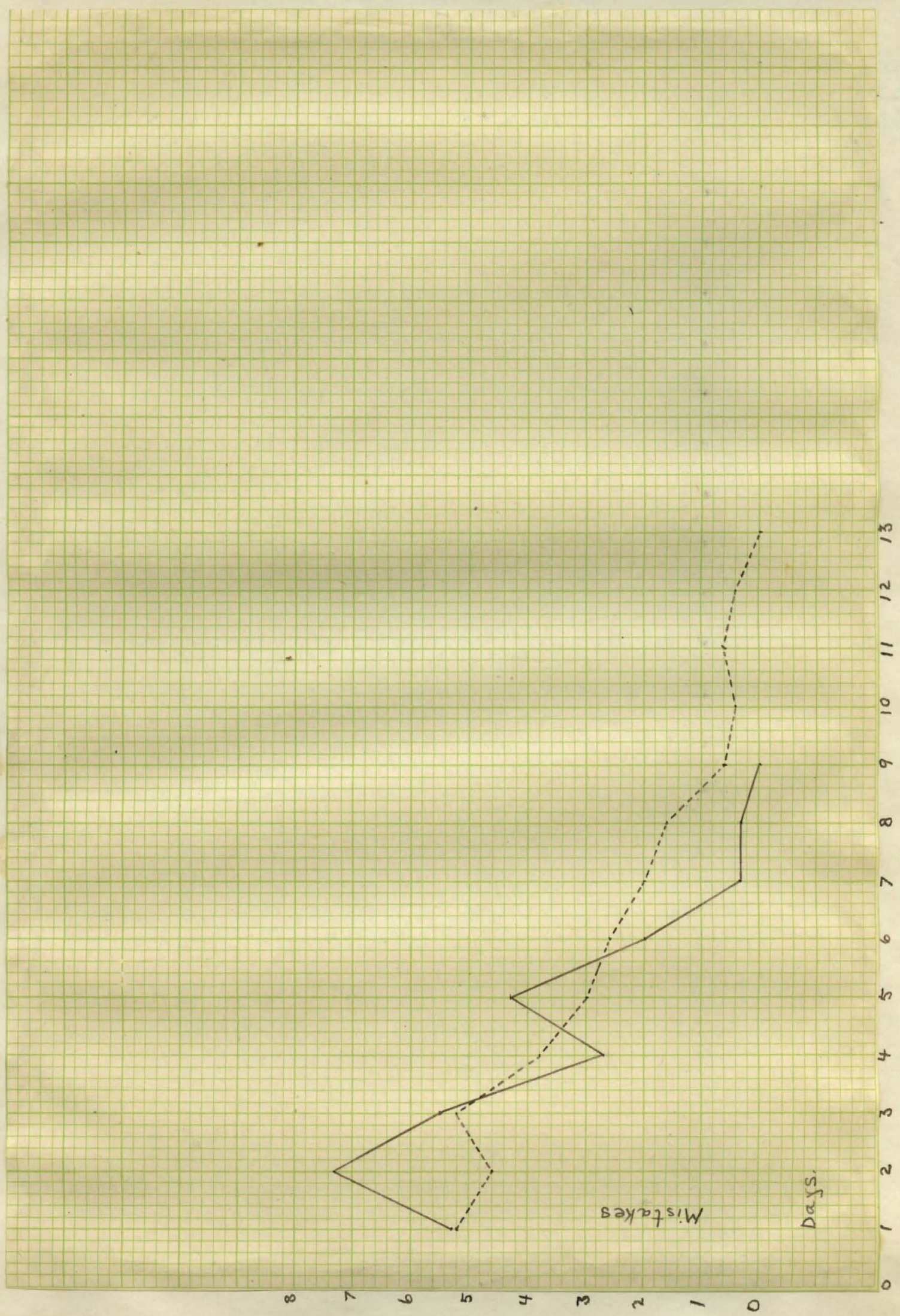




$$
\underline{\mathrm{S}} \underline{\underline{K}} \underline{\underline{I}} \underline{\underline{\mathrm{S}}} \underline{\mathrm{S}} \quad \underline{3} \text {. }
$$

Days. Average no. of Average no. of Average excess per mistakes per rat. mistakes per rat. rat of control over (Experimental) (Control) experimental.

$\begin{array}{cccc}1 & 5.25 & 5.2 & 0.05 \\ 2 & 7.25 & 4.6 & -2.65 \\ 3 & 5.5 & 5.2 & -0.3 \\ 4 & 2.75 & 3.8 & 1.05 \\ 5 & 4.25 & 3 . & -1.25 \\ 6 & 2 . & 2.6 & 0.6 \\ 7 & 0.25 & 2.6 & 1.75 \\ 8 & 0.25 & 1.6 & 1.35 \\ 9 & - & 0.6 & 0.6 \\ 10 & - & 0.4 & 0.4 \\ 11 & - & 0.6 & 0.6 \\ 12 & - & 0.4 & 0.4 \\ 13 & - & - & -\end{array}$


EXCESS OF CONTROIS OVER EXYERIMENTALS - SERIES 3.

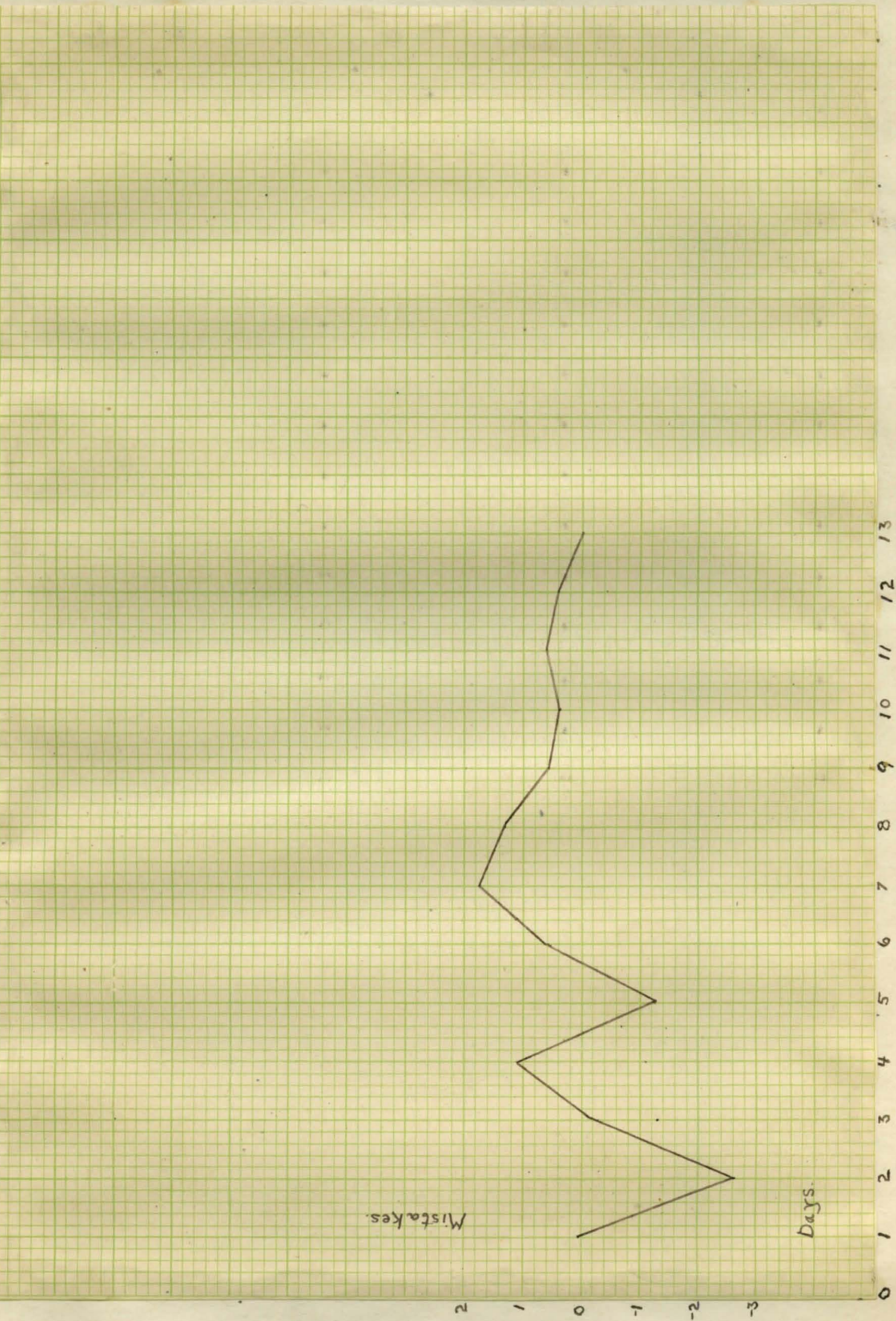


The gray and yellow hooded rats used in Experiment $F$ were born on July 26, 1923. On August 20th, experimental feeding was begun. They were given one gram of hormotone daily for the succeeding period of 81 days. Then each individual, experimental and control, was subjected to the problem box training untii he had mastered his problem. This was considered accomplished when the animal had made one hundred consecutive correct choices, at the rate of ten per day. The feeding of hormotone was continued with each individual until he had solved his problem as stated above. 
EXYERIMENTAL SERIES 4.

FE1; FE2; FE3.

Days. Number of Mistakes. Average number of mistakes for each rat.

1

2

3

4

5

6

7

8
9

4

8

4

5

2

1

0
3

1.3

$2 \cdot 6$

1.3

1.6

0.6

0.3

$* \quad * \quad * \quad * \quad * \quad * \quad *$

CONTROL SERIES 4.

$\mathrm{FCl}$; $\mathrm{FC2} ; \mathrm{FC3}$.

Days. Number of Mistakes. Average number of mistakes for each rat.

1

2

3

4

5

6

7

8
15

13

8

2

4

3

1

0
5

4.3

$2 \cdot 6$

0.6

1.3

1.

0.3

0.3

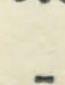




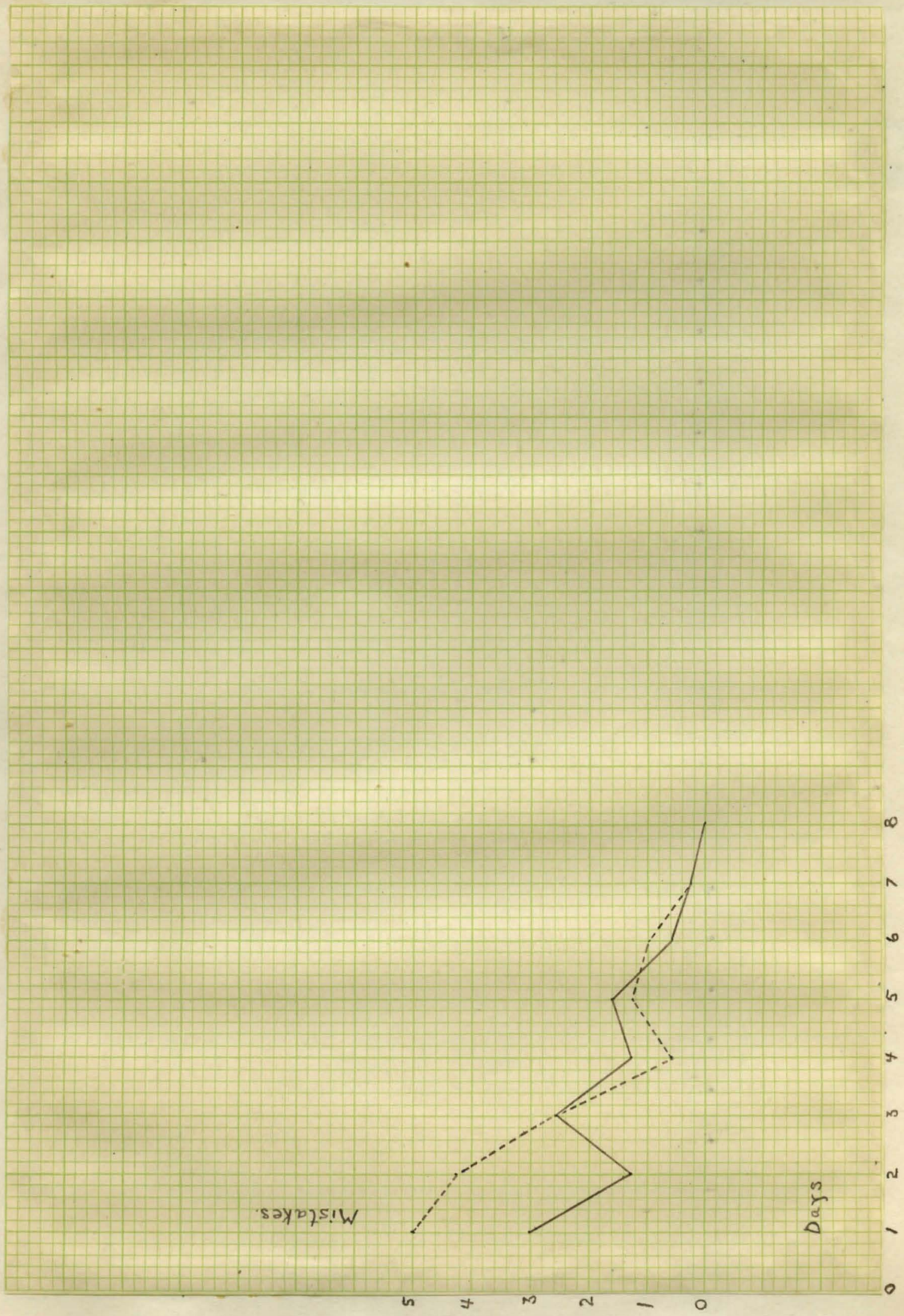




$$
\underline{\mathrm{S}} \underline{\mathrm{E}} \underline{\mathrm{R}} \underline{I} \underline{\mathrm{E}} \underline{\mathrm{S}} \quad \underline{4}
$$

Days. Average no. of Average no. of Average excess per mistakes per rat. mistakes per rat. rat of control over (Experimental) (Control)

$\begin{array}{cccc}1 & 3 . & 5 . & 2 . \\ 2 & 1.3 & 4.3 & 3 . \\ 3 & 2.6 & 2.6 & - \\ 4 & 1.3 & 0.6 & -0.7 \\ 5 & 1.6 & 1.3 & -0.3 \\ 6 & 0.6 & 1 . & 0.4 \\ 7 & 0.3 & 0.3 & - \\ 8 & - & - & -\end{array}$


EXCESS OF CONTROLS OVER EXPERIMENTALS - SERIES 4.

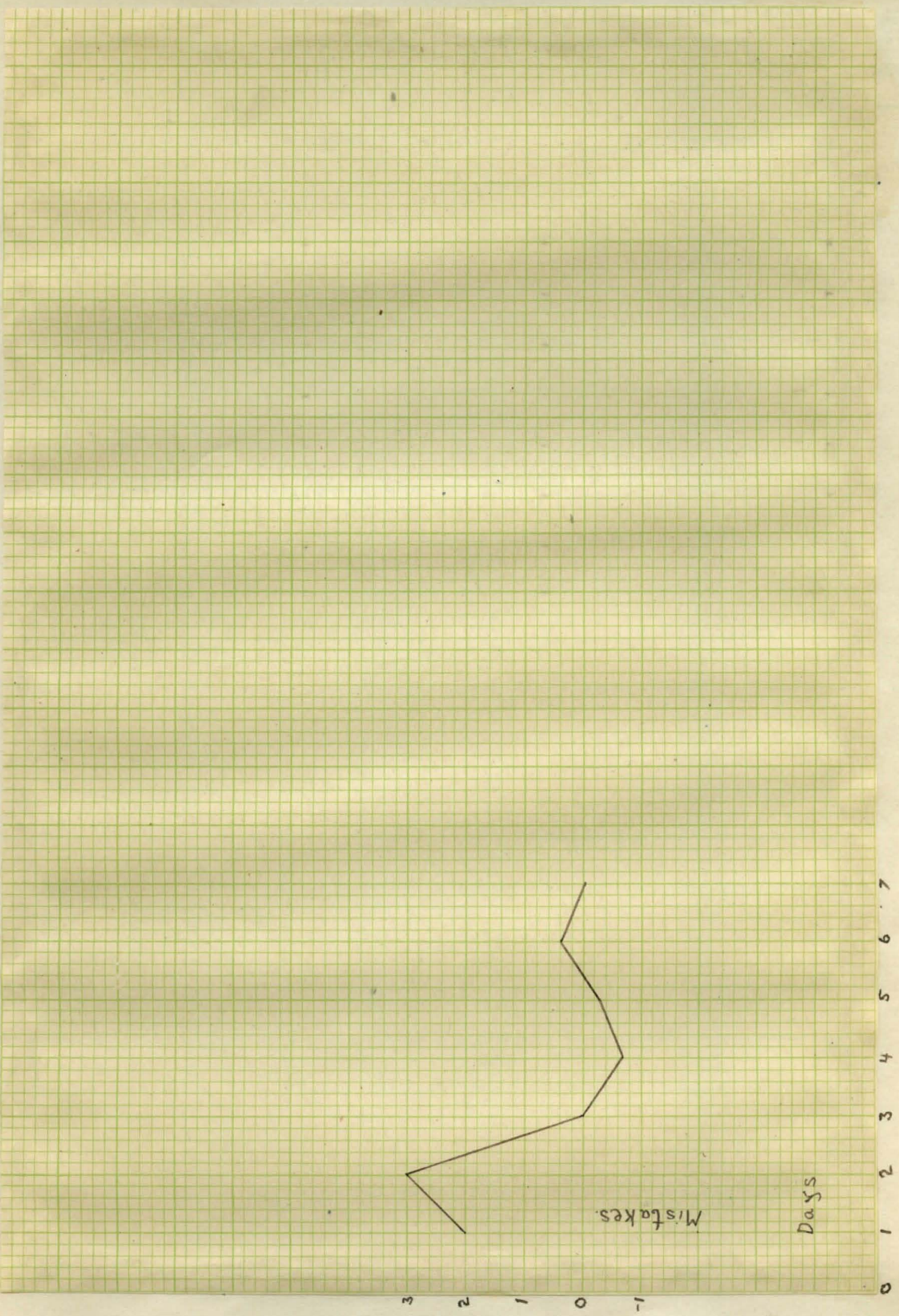


IEARNING AND FORGETTING

Rat. No. of days required No. of days re- Percent that in learning the quired in forgetting forgetting time problem. the problem. is of learning time.

\section{SERIFS 1.}

AEI

8

5

$62 \%$

AE2

12

6

50

AE3

9

4

44

AE4

16

7

43

ACI

18

4

22

AC2

15

0

40

AC3

18

5

28

AC4

18

4

22

* $* * * * * * * *$

\section{SERIES 2.}

$\begin{array}{llll}\mathrm{BE} 1 & 19 & 8 & 42 \\ \mathrm{BE} 2 & 10 & 7 & 42 \\ \mathrm{BE} 3 & 16 & 5 & 31 \\ \mathrm{BE} 4 & 19 & 6 & 31 \\ \mathrm{BE} 5 & 14 & 7 & 50 \\ \mathrm{BC1} & 19 & 5 & 26 \\ \mathrm{BC} 2 & 20 & 7 & 35 \\ \mathrm{BC} 3 & 18 & 4 & 22 \\ \mathrm{BC} 4 & 17 & 0 & 35 \\ \mathrm{BC} 5 & 19 & 5 & 26\end{array}$


Rat. No. of days re- No. of days re- Percent that quired in learning quired in for- forgetting time the problem. getting the is of learning problem.

\section{SERIES 3.}

DE1 (Died)

$\begin{array}{lccc}\text { DE2 } & 8 & 6 & 75 \% \\ \text { DE3 } & 6 & 6 & 100 \\ \text { DE4 } & 6 & 7 & 116 \\ \text { DE5 } & 7 & 6 & 86 \\ \text { DC1 } & 5 & 4 & 80 \\ \text { DC2 } & 14 & 3 & 21 \\ \text { DC3 } & 11 & 6 & 54 \\ \text { DC4 } & 8 & 5 & 62 \\ \text { DC5 } & 10 & 5 & 50\end{array}$

$* * * * * * * * *$ SERIFS 4.

$\begin{array}{llll}\text { FE1 } & 6 & 5 & 83 \\ \text { FE2 } & 7 & 8 & 114 \\ \text { FE3 } & 3 & 5 & 160 \\ \text { FC1 } & 5 & 2 & 40 \\ \text { FC2 } & 7 & 7 & 100 \\ \text { FC3 } & 6 & 8 & 133\end{array}$


AVERAGE NUMBER OF DAYS REQUIRED TO LEARN PROBLEM.

$\begin{array}{lccccc}\text { Series. } & \text { A. } & \text { B. } & \text { D. } & \text { F. } & \text { Average. } \\ \text { Experimentals. } & 11.25 & 16.8 & 6.75 & 5.33 & 10.03 \\ \text { Controls. } & 17.25 & 18.6 & 9.6 & 6.0 & 12.80\end{array}$

In the first series, rat AEl learned the problem in eight days and rat AE3 in nine days. The greatest number of days required was sixteen, by rat AE4. On the contrary, rat AC2 of the controls, learned the problem in fifteen days, or in one day's time less than was required by the highest in the experimental animals of the same series. The other three control animals required eighteen days each.

In the second series, rat BE5 of the experimentals learned the problem in fourteen days; while rats $\mathrm{BE}$ 2 and $B E 3$ required sixteen days; rats $B E I$ and $B E 4$ required nineteen days each. Of the control animals, rat $B C 4$ learned the problem in seventeen days. Rats $\mathrm{BCl}$ and $\mathrm{BC} 5$ learned the problem in the same length of time as their control brothers $\mathrm{BEI}$ and $\mathrm{BE} 4$. Rat $\mathrm{BC2}$ required twenty days to complete the problem.

In the third series, there is a tie between rats $\mathrm{DE} 3$ and $\mathrm{DE} 4$; each required six days to complete the problem. Rat $\mathrm{DE} 5$ required seven days, while rat $\mathrm{DE} 2$ required eight days. On the contrary, rat DCl of the control animals required only five days to learn the 
problem; a day less than that required by any experimental animal of the same series. Rat DC4 required eight days, or the same number of days as required by rat DE2. Rat DC2 required fourteen days to complete the problem or twice as long as rat DE5. Rat DC5 required ten days, or twice as long as rat $\mathrm{DCl}$.

In the fourth series, rat FE3 learned the problem in three days. FEI required six days, the same number as rat FC3. Rat FCI required five days to learn the problem; the least number of days required by the control animals.

Considering the four individual experimental groups, I found that the fourth or F series made the best progress. The average number of days required in learning the problem for the experimentals was 5.33 days, while the controls of the same series required 6.0 days. The third or $D$ series stands next, with an average of 6.75 days for the experimentals and 9.6 days for the controls. The first or A series required an average of 11.25 days for the experimentals and 17.25 days for the controls. The B series had an average of 16.8 days for the experimentals and 18.6 days for the controls. In every case, the experimental animals learned the problem in a fewer number of days than the control animals of the same series. This means, 
of course, that the experimental animals, on the average, learned with fewer trials than the controls, since in every case each animal was given ten trials daily. For example, the B series experimentals required an average of 168 trials, while the $B$ series controls required an average of 186 trials to master their problem. 'the control animals of the $D$ and $F$ series learned the problem in a fewer number of days than the experimental animals of the $A$ and $B$ series. The $D$ and $F$ series required about half the time as that required by the $A$ and $B$ series. The average of the experimental groups shows that they learned the problem in 10.03 days, while the average of the control groups was 12.80 days.

The rats that were trained to go to the lighted side of the problem box learned the problem in the shortest period of time, as compared with those that were trained to go to the dark side. Organotherapy is based upon the activity of endocrine extracts, after they have passed through the alimentary tract and their active principles have reached the blood to be carried by it, just as the corresponding active principles which would have been produced in the normal gland are carried, to bring about the physiological activity in the remote cells which they control by this hormone activity. 
There are signs that endocrine therapy is making faster progress than physiological endocrine research. That is to say, glandular preparations used more or less empirically, are obtaining results, the interpretation of which, physiology has still to determine. This is the case in reference to the present results. The hormotone-fed animals on the average, learn faster than their control litter brothers and sisters. Further, the number of days during which experimental feeding continued prior to the outset of work in the problem box, may also have a modifying effect upon the rate of learning, though the present results cannot be taken to indicate this point conclusively, since the factor of heredity was not "controlled" here. In any event, however, the rats of the $D$ and $F$ series were considerably younger than those of the A and B series, when first put in the problem box and they learned the problem in noticeably fewer trials than the latter. 
SUMMARY AND CONCLUSION. 


\section{-:- SUMMAKY AND CONCLUSION -:-}

It has been shown by the above experiments that diet may have a modifying effect upon the rate of learning, in the problem box method, by lower mammals. Since the experimental agent used was "Hormotone", prepared by the G. W. Carnrick Company of New York City., which consists of extracts of thyroid, ptuitary, ovary and testis in tablet form, each tablet containing one-tenth gr. of desicated thyroid and one-twentieth gr. of whole ptuitary, there is no relation of the present work to the subject of "endocrine balance." However, there is an indication that rats given smaller daily doses, continued over a longer period of time, learm less rapidly than those given larger daily doses for a shorter period of time. The experimental animals of Series A were given one-half tablet of Hormotone daily for 191 days, including the time used in the learning process; the experimental animals of Series B were given $4 / 5$ tablet of Hormotone daily for 93 days, including the leaming period; the experimental animals

of Series D were given $2 / 3$ of a tablet of Hormotone daily for 160 days and those of Series $F$ were given 
one tablet of Hormotone daily for 99 days, including the learning period. The experimental animals of Series $D$ and $F$ learned more rapidly than those of Series $A$ and $B$.

Another point of interest here is the age of the animals at the incidence of experimental feeding. This too, seems to have a differential effect upon the rate of learning, though in this case, this result is obscured by the lack of control of the factor of heredity and the difference in the size of the dally dosage of the four series. Experiments designed to answer the above questions are under way in this laboratory.

The animals of Series A and B were trained to go to the non-illuminated chamber for food; those of Series D and $F$ were trained to go to the illuminated chamber. The latter learned much more rapidly than the former, in the case of the controls as well as the experimentals. The wild rat is a nocturnal animal, so it would seem that the individuals of the $D$ and $F$ Series were handicapped in this respect, as regards those of the first two series. In this connection, the factors of age and heredity must also be borne in mind. Since the controls of Series $D$ and $F$ learned more rapidIy than those of Series $A$ and $B$, heredity may be the effective factor here, though it cannot account for the 
differences in rate of learning between the experimental and control groups of the same individual series.

We may conclude first, that, as far as these experiments are concerned, differences in diet exercise a modifying effect upon the rate of learning in the problem box method; second, that there are indications for this work that both the age of the animal at the beginning of training and the amount of the daily dosage and its continuation also may modify the rate of learning.

It is recognized that the very small number of animals concerned here does not justify one in drawing any final conclusions from these results. To supply this "lack of quantity", other experiments are in progress.

Mr. E. G. Causey, working in this laboratory, has found in the case of a single litter of rats, that trypsogen fed to one-half of the litter, caused these experimental animals to exhibit a definitely more rapid rate of growth than their control brothers and sisters. This would seem to be corraborative of my results since the demonstrable effects of differences in diet are probably the expression of induced modifications in the physiological processes concerned. 
Further, it is conceivable that a more rapid physical development, implying as it does, a more rapid increase in the mass of the cerebral tissue, may be correlated with a more rapid development in the ability of the animal to form associations of ideas. 


\section{BIBLIOGRAFHY}

$\therefore$ 


\section{$\underline{B} \underline{I} \underline{B} \underline{L} \underline{I} \underline{O} \underline{G} \underline{R} \underline{A} \underline{\underline{P}} \underline{H} \underline{\underline{Y}}$}

Darwin, C. R.; Descent of Man, New York, 1874.

Hobhouse, L. T., Mind in Evolution, London, 1901.

Holmes, S. J., The Evolution of Animal Intelligence, N.Y.,'Il. Jennings, H. S., Behavior of the Lower Organisms, N.Y., 1915. Morgan, C. I., Animal Behavior, Lonaon, 1900.

Romanes, G. J., Jellyfish, Starfish, and Sea Urchins, N.Y. \$85. Spencer, H., Principles of Psychology, 3rd ed. N.Y.,1894. Thorndike, E., Animal Intelligence, An experimental study of associative processes: Psych.Rev. Suppl.2, 1898. Wagner, G., On Some Movements and Reactions of Hydra:Quart. Journ. Micr. Sci., XLVIII, 585-622., 1905.

Wallace, A. B., The Malay Archipelago, 3rd ed., London, 1872. Washburn, M. F., The Animal Mind, New York, 1913. Wilson, E. B., The Heliotropism of Hydra, Amer. Nat.,N.Y.,'9l. Yerkes, R. M. and Huggins, G. E., Habit Formation in the Crawfish Cambarus Affinis: Harv.Psy.Studies, vol.I, 565-577, Neqw York, 1903. 